\title{
Training load monitoring in team sports: A novel framework separating physiological and biomechanical load-adaptation pathways
}

\author{
Jos Vanrenterghem ${ }^{1,2}$, Niels Jensby Nedergaard ${ }^{2}$, Mark A. Robinson ${ }^{2}$, Barry Drust ${ }^{2}$ \\ ${ }^{1}$ Faculty of Kinesiology and Rehabilitation Sciences, KU Leuven, Belgium \\ ${ }^{2}$ Research Institute for Sport and Exercise Science, Liverpool John Moores University, UK
}

February 2017, Accepted for publication in Sports Medicine

\begin{abstract}
There have been considerable advances in monitoring the training load in running-based team sports in recent years. Novel technologies nowadays offer ample opportunities to continuously monitor the activities of a player. These activities lead to internal biochemical stresses on the various physiological sub-systems. However, they also cause internal mechanical stresses on the various musculoskeletal tissues. Based on the amount and periodization of these stresses, the sub-systems and tissues adapt. So by monitoring external loads one hopes to estimate internal loads to predict adaptation, and this through understanding the load-adaptation pathways. We propose a new theoretical framework in which physiological and biomechanical load-adaptation pathways are considered separately, shedding a new light on some of the previously published evidence. We hope that it can help the various practitioners in this field (trainers, coaches, medical staff, sport scientists) to align their thoughts when considering the value of monitoring load, and that it can help researchers design experiments that can better rationalise training load monitoring for improving performance whilst preventing injury.
\end{abstract}

\section{Key points:}

1. Easy access to a huge diversity of training load data in modern team sports has caused confusion about the load-adaptation mechanisms to which different data are expected to be associated.

2. We propose a new theoretical framework in which physiological and biomechanical load-adaptation pathways are considered separately, and for which the distinction between internal and external load measures is revisited.

3. Load-adaption pathways have different response rates, which has consequences for the planning of training and/or rehabilitation sessions when attempting to enhance performance and prevent (re-)injury. 


\section{Introduction}

Team sports are demanding activities and when players are challenged to an appropriate level this can lead to physiological adaptations of the aerobic, cardiovascular and muscular systems. These adaptations benefit sporting performance through increased endurance, speed, strength, or power. Excessive amounts of training can however lead to overload of the system's capacity, and increased risk of injury and illness. Otherwise, insufficient training may annihilate the performance benefits. It is thus generally accepted that players should be challenged adequately through appropriate periodization of their activities, allowing optimal recovery between bouts of activity to achieve the desired physiological adaptations of the system (1). The activities performed by the athlete represent an external load, yet the abovementioned physiological adaptations come about because of internal load, and this primarily in the form of biochemical stresses.

Besides biochemical stresses, the activities performed by the athlete also lead to mechanical stresses on the different tissues that comprise the musculoskeletal system, that is, on cartilage, bone, muscle, and tendon tissue. Basic tissue engineering science has demonstrated how mechanical stresses are directly related to tissue damage and repair (e.g. (2)), showing that homeostasis is triggered directly through a narrow window of load intensities. This means that as a consequence of the mechanical stresses structural and functional adaptations of the musculoskeletal system take place. In the applied field of training load monitoring this mechanical load-adaptation pathway has been largely overlooked. We therefore propose a novel framework in which the physiological and biomechanical load-adaptation pathways are considered separately, as schematically presented in Figure 1. Albeit oversimplified, for physiological load-adaptations one could seek analogy in the workings of a car engine, where the key focus is on the consumption of fuel and oxygen. Sticking with this car analogy, the biomechanical load-adaptations could be represented by the suspension system, where the key focus is on keeping the mechanical properties intact. The aim of this paper is to present how some scientific evidence on measures of external and internal training load could be interpreted according to these separate pathways, in the hope that this may ultimately help resolve a current lack of consensus in measures of training load (3). 


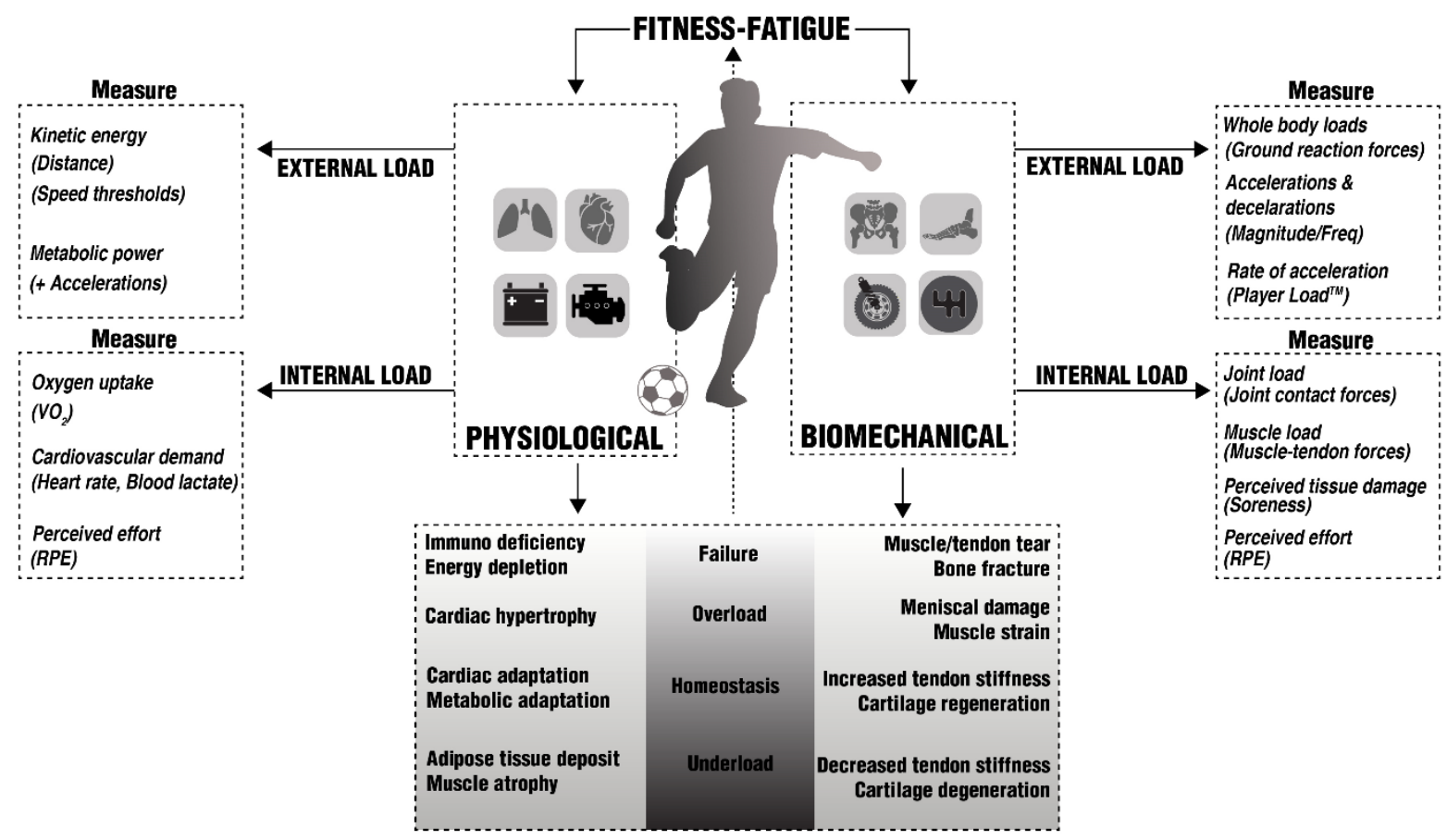

Figure 1: A new player load monitoring framework outlining the cyclical nature in which physiological and biomechanical load leads to adaptation of the biological system as a whole.

\section{Monitoring external load}

In the past few years player monitoring systems based on Global Positioning Systems (GPS) have shown to be reliable and valid for monitoring player activity levels in running-based team sports (410). Particularly kinematic variables such as distance covered or some form of the average running velocity are physiologically relevant, as they can be representative of energy consumption through the use of so-called 'metabolic power equations'. This works reasonably well for constant speed sporting activities $(11,12)$, however accelerating and decelerating the body involves greater energetic cost than maintaining constant speed (13), which has led to the integration of GPS-based accelerations (second derivative of displacement) into adapted power equations for team sports (14-16). Whilst this was shown to improve estimates of energetic load (15), the fact that team sports involve non-steady state locomotion makes it very difficult to accurately estimate metabolic power, added with the fact that 
reliability and validity of velocity-based measures is lower for movements with higher accelerations $(10,17)$, and the accuracy of GPS-based acceleration signals is known to be limited (18).

The biomechanical component of training load (Figure 1 right hand side) depends largely on propulsive and breaking forces against the ground. It has been recognised that players in team sports undertake some 500 rapid accelerations and decelerations in a single match (19). The mechanical stresses on soft tissues (internal load) come from these external kinetic demands of absorbing high forces from the impact with the environment and generating high forces to push off against the ground (remember the car suspension analogy). Measuring these external forces directly is possible but difficult outside of a laboratory. Instead, measuring the accelerations based on Newton's second law (with a certain mass, accelerations are proportional to the external forces acting on the body) is more feasible. The availability of low-cost inertial sensors has led to the integration of accelerometers in commercially available GPS units, and this in turn has led to an expansion of the literature towards evaluating reliability of accelerometry-based variables (20-23) and their utility to assess training load in various situations (24-27) and sporting populations $(23,24,28-30)$.

Accelerometers provide a continuous signal at a high measuring frequency (currently $100 \mathrm{~Hz}$ in most commercially available units) and so providing a summative measure of this signal is needed to represent the extent to which the body has been 'shaken up'. A number of these summative measures have been proposed such as 'Dynamic Stress Load' (31), 'New Body Load' (32) or 'Force Load' (33), yet arguably the most commonly reported measure has been Player $\operatorname{Load}^{\mathrm{TM}}(20,28)$. The premise of these summative measures is that an estimate of the external biomechanical load can be provided through accumulating the rates of acceleration. Recent studies have used PlayerLoad ${ }^{\mathrm{TM}}$ values to monitor training load in season and between matches $(34,35)$ and some studies determined typical profiles in various team sports $(34,36-39)$. Scientists have attempted to relate this to the physiological load (external or internal measures), similar to what is commonly done in physical activity monitoring (as reviewed in $(40,41))$. For example, one study demonstrated moderate to high relationships between PlayerLoad ${ }^{\mathrm{TM}}$ and distance covered $(29,42)$, while other studies have demonstrated a moderate to high relationship between PlayerLoad ${ }^{\mathrm{TM}}$ and ratings of perceived exertion (RPE) (42-44) 
and trivial to moderate relationship between PlayerLoad ${ }^{\mathrm{TM}}$ and $\dot{V} \mathrm{O}_{2}$ or heart rate data, respectively $(20,42,45)$. These relationships between measures of physiological and biomechanical loads lack a solid foundation, except for the fact that in running-based team sports the variations in both types of loads are generally experienced together. In fact, this was recognised in three papers, where based on the poor relationship it was suggested that accumulated accelerometer-based outcomes such as PlayerLoad ${ }^{\mathrm{TM}}$ measure a different construct of the training process than internal physiological load measures such as RPE or HR $(35,38,42)$. Rather, these measures are valuable to estimate the extent to which the player through their activities experiences accelerations and hence biomechanical load of the body as a whole. Considering that the trunk is the body segment with highest mass, attaching an accelerometer to the trunk provides the closest measure of the accelerations of the whole body. The relationship between trunk and whole-body accelerations is not perfect but at least offers a starting point for measuring external load from a biomechanical perspective (46).

\section{Monitoring internal load}

From a physiological perspective, if the external load is increased by running further and faster, then that will lead to increased metabolic energy cost $(47,48)$. This metabolic energy is needed to drive muscle contractions, which mainly require the provision of carbohydrates, fats and proteins, and the provision of oxygen in the case of aerobic energy-burning processes. These are primarily challenges to the cardiorespiratory system and therefore measures of internal physiological load are most often related to oxygen consumption and cardiac output. The various techniques and measures of internal load have recently been reviewed elsewhere $(49,50)$, and here we will focus on some of the most commonly used ones. For example, cardiorespiratory output is easily assessed in the field by recording heart rates or related outcome variables (e.g. Training Impulse TRIMP as in (51)) and has seen more interest than oxygen consumption which needs semi-invasive lab-based techniques. Both cardiorespiratory measures ignore the anaerobic contributions, for which blood lactate values have been assessed $(52,53)$. Blood lactate values reflect an accumulation of previous efforts rather than a measure of the last bout of anaerobic contribution (23). Second, a less direct measure of internal 
physiological load is the subjective Rating of Perceived Exertion (RPE). This is seen as an index for training stress, and has seen great popularity in the field because of its ease in administration $(51,54,55)$. Despite the subjective nature of RPE it has been shown to correlate well with a number of heart rate based internal load indicators when multiplied by the duration of the session (56), which could justify its use as an estimate of internal physiological load. Altogether, a number of techniques to monitor internal physiological load, albeit indirectly, have become established in running-based team sports, which is not yet the case for monitoring internal biomechanical load.

Monitoring mechanical stresses on the musculoskeletal system requires measurement of variables such as joint contact forces or muscle-tendon forces. Advanced biomechanical work is currently being undertaken to estimate such forces in a lab environment through musculoskeletal modelling approaches (e.g., 57). At present this is impossible in a field context, and the relationship between aforementioned measures of external load (e.g. from trunk accelerometry) and tissue specific mechanical stresses are insufficiently understood, so the question is whether indirect measures of mechanical stresses to musculoskeletal tissue are available. A first candidate is in fact RPE, which was earlier proposed as a measure of internal physiological load. We would argue that the biomechanical load can also lead to a perception of how hard a session was, and that a generic RPE probably reflects both types of internal load (biochemical and mechanical stress). In one study the session-based RPE (RPE multiplied by the duration of the session) was actually explained by acceleration-based measures at least to the same extent as by measures of energy expenditure, which would suggest that it veers towards internal biomechanical load (31). By asking the player to be specific in how much their 'breathing' was affected or how much their 'legs' were affected, one may well be able to separate their perceptions of physiological and biomechanical load. The idea of differential RPE's is not novel with 'breathlessness' and 'leg exertion' closely reflecting the distinction between physiological and biomechanical load, respectively (58). Other measures of how mechanically damaging training activities have been for the musculo-skeletal system is the rating of muscle soreness $(59,60)$, the Profile of Moods (POMS) questionnaire, or the Recovery-Stress Questionnaire (REST-Q) (61). Important disadvantages of these measures however is that these are 
best measured one or two days after the session took place rather than immediately after the session, taking into account the principle of delayed onset of muscle soreness (DOMS), and that the repeated bout effect quickly leads to less detectable or absence of muscle soreness (62). Therefore, a more direct indicator of muscle damage is desired and this is possible through measuring serum Creatine Kinase (CK) levels (63). In fact, increased CK levels have been shown to moderately relate to acceleration-based player load in Rugby League (60) and in Australian Rules Football (64), evidencing the relationship between accumulated tissue trauma (internal load) and external biomechanical loads. A limitation of CK levels as indicator for accumulated tissue damage is however that its measurement is difficult, that a single acute macro trauma likely overrides the measure of accumulated trauma, and that there is still a similar repeated bout effect as with measures of muscle soreness. In summary, internal loads can be difficult to measure directly, both from a physiological and biomechanical perspective, but subjective assessments through for example differential RPE's may well be a suitable indirect alternative.

\section{Adaptation}

Principles of load and the assumed consequent adaptation are generally accepted in a physiological context of training load monitoring, both central (heart, lungs, nervous system) or peripherally (capillarization, fibre subtypes, molecular, oxidative, glycolytic). In the context of team sports, these have been reviewed extensively elsewhere (e.g. 48,63). To our knowledge this principle has however not yet been formulated in an explicitly biomechanical context. Whilst a recent editorial (66) and review (54) have already alluded to this, we believe that with some more detailed biomechanical understanding the distinct biomechanical load-adaptation pathway in the proposed framework can be further justified.

Biomechanical adaptations take place through mechanical stresses to the various musculoskeletal tissues. Muscular adaptations are perhaps best known and the most responsive to mechanical stimuli, with considerable adaptations to mechanical properties such as fascicle length, pennation angle, and muscle thickness (for an excellent review on this matter, see (67)). Similar to how muscle properties 
depend on mechanical stimuli, the synthesis of other soft tissues and their molecular turnover depends on the mechanical stresses to which they are exposed. For example, articular cartilage which is regularly exposed to high levels of stress has a higher cell volume (68), has a higher content of proteoglycans for better synthesis $(69,70)$, and is stiffer (71). Similarly, tendons undergo structural adaptations that change their modulus (72), as well as size adaptations based on habitual loading patterns (73). Whilst it is commonly known that excessive mechanical load accumulation can generate structural failure in the form of chronic injuries (e.g. stress fractures, tendinitis), the more subtle biomechanical adaptations are often overlooked. This is probably because they are less obvious to observe, and they tend to have a slower response rate than physiological adaptations.

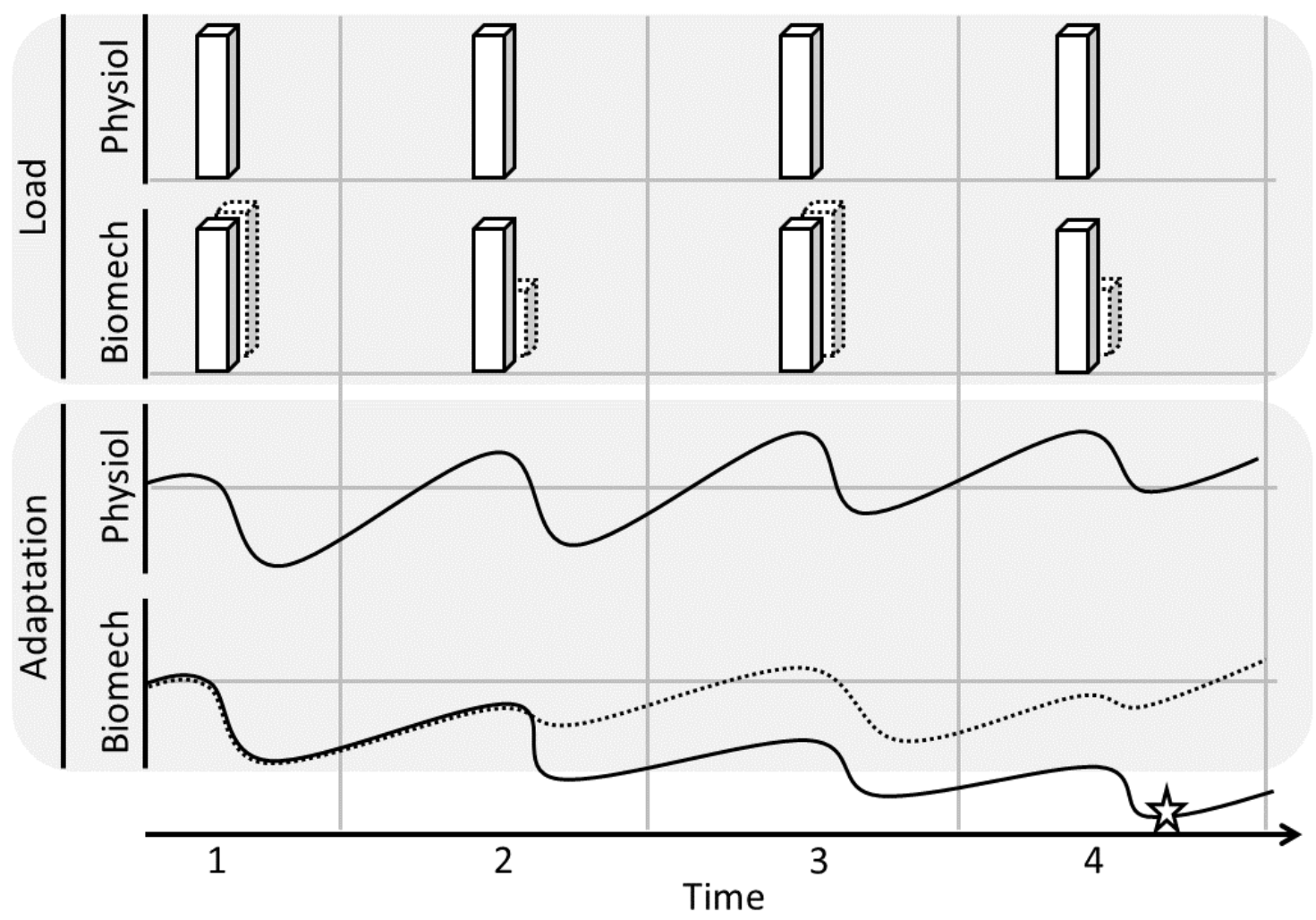

Figure 2: Theoretical example of how different time frames between physiological and biomechanical adaptation may need different periodization between physiological and biomechanical load. The dotted blocks represent an alternative biomechanical load periodization, leading to an improved biomechanical adaptation profile as the dotted line. 
Differences in response rates can have important consequences, as is demonstrated in Figure 2. In the top part of Figure 2 a sequence of physiological and biomechanical internal loading is delivered to the system in the form of training sessions with a certain amount of load, for example with two day intervals in between sessions. In the bottom part of Figure 2, the associated changes to the state of physiological and biomechanical systems is shown through the solid lines, which could be glycogen availability within the muscle (physiological), and stiffness of a tendon (biomechanical), just to name two. When hypothetically taking a biomechanical response rate that is twice as long as the physiological response rate, the physiological adaptation has reached supercompensation and the next training session comes at the right time to achieve gradual improvement of the system. However, due to its slower response rate biomechanical adaptation is still incomplete, meaning that the next biomechanical load arrives at a time when the tissue is still weakened, causing gradual degeneration until a critical weakness and tissue failure may be reached (as indicated by the star in Figure 2). Perhaps the amount of biomechanical load should be reduced at times of weakness (dashed biomechanical load block with dashed biomechanical adaptation line at time point 2), allowing for supercompensation in the tissue properties to take place before a higher biomechanical load is delivered at time point 3 . This theoretical example of how periodisation could pursue optimal sequencing of load, is only possible if one is able to separately control physiological and biomechanical load. We will discuss in the next section a couple of examples of how this can be achieved in running-based team sports.

\section{Differentiating physiological and biomechanical load}

Separate modification of physiological and biomechanical load is already common practise in rehabilitation of lower extremity musculo-skeletal injuries. Aqua jogging exercises and more recently exercises on an anti-gravity (also called lower-body positive-pressure) treadmill have become common practice during the rehabilitation of athletic injuries (74). Such exercises aim to provide physiological load with reduced biomechanical load, and for both types of exercises ground reaction forces are reduced by up to $20 \%$ depending on modality $(75,76)$. The benefit of these exercises is that 
despite low biomechanical load they involve walking or running locomotion that is only slightly altered due to water resistance (77), so these are favoured against cycling exercises even if tissue loading due to impact is known to be negligible during cycling. Another example of load differentiation can be found in the load alterations as observed when playing small-sided games. Studies have found that reducing pitch size reduces the physiological load $(78,79)$, but that it likely increases the biomechanical load $(79,80)$. Another example is the use of high-intensity interval training (HIT) which delivers a high physiological load but with low biomechanical load. As suggested in a recent review on HIT (81) this could therefore be a practical example of the alternative training session which one may wish to schedule at time points 3 and 4 in Figure 2. A final example is running on sand, where it was found to be possible to perform maximal intensity sprints involving high physiological load but reduce the biomechanical load (impact) considerably compared to what is typically experienced on a harder surface (e.g. concrete or grass) (82).

\section{Conclusion}

Huge amounts of data can be monitored on a daily basis. Turning this data into relevant information for players, coaches and therapists can be an extremely daunting challenge for a novice sports scientist entering the professional sporting environment. With this paper we would like to encourage not only sport scientists to pursue further research according to a framework that differentiates physiological and biomechanical load-adaptation pathways, but also the broader coaching and sports medical staff in running-based team sports to venture into some of the biomechanical literature reviewed in this paper and sharpen their views on how monitoring training load can be a valuable tool for improving performance whilst preventing injury.

\section{Funding}

No financial support was received for the conduct of this study or preparation of this article.

\section{Conflict of interest}


Jos Vanrenterghem, Niels Nedergaard, Mark Robinson, and Barry Drust declare that they have no conflict of interest relevant to the views shared in this article.

\section{References}

1. Bompa TO, Haff GG. Periodization: Theory and methodology of training. Human Kinetics Publishers; 2009.

2. Wang T, Lin Z, Day RE, Gardiner B, Landao-Bassonga E, Rubenson J, et al. Programmable mechanical stimulation influences tendon homeostasis in a bioreactor system. Biotechnol Bioeng. 2013;110(5):1495-507.

3. Cummins C, Orr R, O'Connor H, West C. Global positioning systems (GPS) and microtechnology sensors in team sports: A systematic review. Sport Med. 2013;43(10):102542.

4. Duffield R, Reid M, Baker J, Spratford W. Accuracy and reliability of GPS devices for measurement of movement patterns in confined spaces for court-based sports. J Sci Med Sport. 2010;13(5):523-5.

5. Gray AJ, Jenkins D, Andrews MH, Taaffe DR, Glover ML. Validity and reliability of GPS for measuring distance travelled in field-based team sports. J Sports Sci. 2010;28(12):1319-25.

6. Johnston RJ, Watsford ML, Pine MJ, Spurrs RW, Sporri D. Assessment of $5 \mathrm{~Hz}$ and $10 \mathrm{~Hz}$ GPS units for measuring athlete movement demands. Int J Perform Anal Sport. 2013;13(1):262-74.

7. Köklü Y, Arslan Y, Alemdaroglu U, Duffield R. The accuracy and reliability of Spi ProX global positioning system devices for measuring movement demands of team sports. J Sports Med Phys Fitness. 2015;55(5):471-7.

8. MacLeod H, Morris J, Nevill A, Sunderland C. The validity of a non-differential global 
positioning system for assessing player movement patterns in field hockey. J Sports Sci. 2009;27(2):121-8.

9. Portas MD, Harley JA, Barnes CA, Rush CJ. The validity and reliability of $1-\mathrm{Hz}$ and $5-\mathrm{Hz}$ Global Positioning Systems for linear, multidirectional, and soccer-specific activities. Int J Sports Physiol Perform. 2010;5(4):448-58.

10. Varley MC, Fairweather IH, Aughey RJ. Validity and reliability of GPS for measuring instantaneous velocity during acceleration, deceleration, and constant motion. J Sports Sci. 2012;30(2):121-7.

11. de Koning JJ, Bobbert MF, Foster C. Determination of optimal pacing strategy in track cycling with an energy flow model. J Sci Med Sport. 1999;2(3):266-77.

12. Koning JJ De, Foster C, Lampen J, Hettinga F, Bobbert MF, Koning D, et al. Experimental evaluation of the power balance model of speed skating. J Appl Physiol. 2005;98:227-33.

13. di Prampero PE. Sprint running: a new energetic approach. J Exp Biol. 2005;208(14):2809-16.

14. Osgnach C, Poser S, Bernardini R, Rinaldo R, Di Prampero PE. Energy cost and metabolic power in elite soccer: A new match analysis approach. Med Sci Sports Exerc. 2010;42(1):1708.

15. Gaudino P, Iaia FM, Alberti G, Strudwick AJ, Atkinson G, Gregson W. Monitoring Training in Elite Soccer Players : Systematic Bias between Running Speed and Metabolic Power Data Monitoring Training in Elite Soccer Players : Systematic Bias between Running Speed and Metabolic Power Data. Int J Sports Med. 2013;34(11):963-8.

16. Sheppard JM, Young WB, Doyle TLA, Sheppard TA, Newton RU. An evaluation of a new test of reactive agility and its relationship to sprint speed and change of direction speed. J Sci Med Sport. 2006;9(4):342-9. 
17. Akenhead R, French D, Thompson KG, Hayes PR. The acceleration dependent validity and reliability of 10Hz GPS. J Sci Med Sport. 2014;17(5):562-6.

18. Stevens TGA, De Ruiter CJ, Van Niel C, Van De Rhee R, Beek PJ, Savelsbergh GJP. Measuring acceleration and deceleration in soccer-specific movements using a local position measurement (lpm) system. Int J Sports Physiol Perform. 2014;9(3):446-56.

19. Bloomfield J, Polman R, O’Donoghue P. Physical demands of different positions in FA Premier League soccer. J Sport Sci Med. 2007;6(1):63-70.

20. Barrett S, Midgley A, Lovell R. PlayerLoad ${ }^{\mathrm{TM}}$ : Reliability, convergent validity, and influence of unit position during treadmill running. Int J Sports Physiol Perform. 2014;9(6):945-52.

21. Boyd LJ, Ball K, Aughey RJ. The relaibility of MinimaxX accelerometers for measuring physical activity in Australian football. Int J Sport Physiol Perform. 2011;6:311-21.

22. Kelly SJ, Murphy AJ, Watsford ML, Austin D, Rennie M. Reliability and validity of sports accelerometers during static and dynamic testing. Int J Sports Physiol Perform. 2015;10(1):106-11.

23. Barron D, Atkins S, Edmundson C, Fewtrell D. Accelerometer derived load according to playing position in competitive youth soccer. Int J Perform Anal Sport. 2014;14(3):734-43.

24. Cormack SJ, Smith RL, Mooney MM, Young WB, O'Brien BJ. Accelerometer load as a measure of activity profile in different standards of netball match play. Int J Sports Physiol Perform. 2014;9(2):283-91.

25. Page R, Marrin K, Brogden C, Greig M. Biomechanical and physiological response to a contemporary soccer match-play simulation. J Strength Cond Res. 2015;29(10):2860-6.

26. Wundersitz DWT, Gastin PB, Richter C, Robertson SJ, Netto KJ. Validity of a trunk-mounted accelerometer to assess peak accelerations during walking, jogging and running. Eur J Sport 
Sci. 2015;15(5):382-90.

27. Wundersitz DWT, Gastin PB, Robertson S, Davey PC, Netto KJ. Validation of a trunkmounted accelerometer to measure peak impacts during team sport movements. Int J Sports Med. 2015;36(9):742-6.

28. Boyd LJ, Ball K, Aughey RJ. Quantifying external load in australian football matches and training using accelerometers. Int J Sports Physiol Perform. 2013;8(1):44-51.

29. Polglaze T, Dawson B, Hiscock DJ, Peeling P. A comparative analysis of accelerometer and time - Motion data in elite men's hockey training and competition. Int J Sports Physiol Perform. 2015;10(4):446-51

30. Terje D, Jørgen I, Gertjan E, Geir Håvard H, Ulrik W. Player load, acceleration, and deceleration during 45 competitive matches of elite soccer. J Strength Cond Res. 2015;30(2):1-28.

31. Gaudino P, Iaia FM, Strudwick AJ, Hawkins RD, Alberti G, Atkinson G, et al. Factors Influencing Perception of Effort (Session-RPE) During Elite Soccer Training. Int J Sports Physiol Perform. 2015;10(7):860-4.

32. Ehrmann FE, Duncan CS, Sindhusake D, Franzsen WN, Greene DA. GPS and Injury Prevention in Professional Soccer. J Strength Cond Res. 2016;30(2):360-7.

33. Colby M j., Dawson B, Heasman J, Rogalski B, Gabbett TJ. Accelerometer and GPS-derived running loads and injury risk in elite Australian footballers. J Strength Cond Res. 2014;28(8):2244-52.

34. Kempton T, Sullivan C, Bilsborough JC, Cordy J, Coutts AJ. Match-to-match variation in physical activity and technical skill measures in professional Australian Football. J Sci Med Sport. 2015;18(1):109-13. 
35. Scott BR, Lockie RG, Knight TJ, Clark AC, De Jonge XAKJ. A comparison of methods to quantify the in-season training load of professional soccer players. Int J Sports Physiol Perform. 2013;8(2):195-202.

36. Chandler PT, Pinder SJ, Curran JD, Gabbett TJ. Physical demands of training and competition in collegiate netball players. J Strength Cond Res. 2014;28(10):2732-7.

37. Polley CS, Cormack SJ, Gabbett TJ, Polglaze T. Activity profile of high-level Australian lacrosse players. J Strength Cond Res. 2015;29(1):126-36.

38. Scanlan AT, Wen N, Tucker PS, Dalbo VJ. The relationships between internal and external training load models during basketball training. J Strength Cond Res. 2014;28(9):2397-405.

39. Sullivan C, Bilsborough JC, Cianciosi M, Hocking J, Cordy JT, Coutts AJ. Factors affecting match performance in professional Australian football. Int J Sport Physiol Perform. 2014;9:561-6.

40. Chen KY, Bassett DR. The technology of accelerometry-based activity monitors: Current and future. Med Sci Sports Exerc. 2005;37(11 SUPPL.):S490-500.

41. Yang CC, Hsu YL. A review of accelerometry-based wearable motion detectors for physical activity monitoring. Sensors. 2010;10(8):7772-88.

42. Casamichana D, Castellano J, Calleja-Gonzalez J, San Roman J, Castagna C. Relationship between indicators of training load in soccer players. J Strength Cond Res. 2013;27(2):369-74.

43. Gallo T, Cormack S, Gabbett T, Williams M, Lorenzen C. Characteristics impacting on session rating of perceived exertion training load in Australian footballers. J Sports Sci. 2014;414(August 2014):1-9.

44. Weston M. Difficulties in Determining the Dose-Response Nature of Competitive Soccer Matches. J Athl Enhanc. 2013;2(1):1-2. 
45. Walker EJ, McAinch AJ, Sweeting A, Aughey RJ. Inertial sensors to estimate the energy expenditure of team-sport athletes. J Sci Med Sport. 2016;19(2):177-81.

46. Nedergaard NJ, Robinson MA, Eusterwiemann E, Drust B, Lisboa PJ, Vanrenterghem J. The Relationship Between Whole-Body External Loading and Body-Worn Accelerometry During Team Sports Movements. Int J Sports Physiol Perform. 2017;12(1):18-26.

47. Di Prampero PE, Atchou G, Brückner J-C, Moia C. The energetics of endurance running. Eur J Appl Physiol Occup Physiol. 1986;55(3):259-66.

48. Wallace LK, Slattery KM, Coutts AJ. A comparison of methods for quantifying training load: Relationships between modelled and actual training responses. Eur J Appl Physiol. 2014;114(1):11-20.

49. Cardinale M, Varley MC. Wearable training monitoring technology: applications, challenges and opportunities. Int J Sports Physiol Perform. 2017;Published.

50. Impellizzeri FM, Rampinini E, Marcora SM. Physiological assessment of aerobic training in soccer. J Sports Sci. 2005;23(6):583-92.

51. Borresen J, Lambert MI. The quantification of training load, the training response and the effect on performance. Sport Med. 2009;39(9):779-95.

52. Bangsbo J, Iaia FM, Krustrup P. The Yo-Yo Intermittent Recovery Test. Sport Med. 2008;38(1):37-51.

53. Ekblom B. Applied Physiology of Soccer. Sport Med. 1986;3(1):50-60.

54. Gabbett TJ. The training-injury prevention paradox: should athletes be training smarter and harder? Br J Sports Med. 2016;50:273-80.

55. Mclaren SJ, Weston M, Smith A, Cramb R, Portas MD. Variability of physical performance and player match loads in professional rugby union. J Sci Med Sport. 2015;19(6):493-7. 
56. Impellizzeri FM, Rampinini E, Coutts AJ, Sassi A, Marcora SM. Use of RPE-based training load in soccer. Med Sci Sports Exerc. 2004;36(6):1042-7.

57. Saxby DJ, Bryant AL, Modenese L, Gerus P, Killen B, Konrath J, et al. Tibiofemoral Contact Forces in the Anterior Cruciate Ligament-Reconstructed Knee. Med Sci Sports Exerc. 2016;48(11):2195-206.

58. Weston M, Siegler J, Bahnert A, McBrien J, Lovell R. The application of differential ratings of perceived exertion to Australian Football League matches. J Sci Med Sport. 2015;18(6):704-8.

59. McNamara DJ, Gabbett TJ, Naughton G, Farhart P, Chapman P. Training and competition workloads and fatigue responses of elite junior cricket players. Int J Sports Physiol Perform. 2013;8(5):517-26.

60. McLellan CP, Lovell DI, Gass GC. Biochemical and endocrine responses to impact and collision during elite rugby league match play. J Strength Cond Res. 2011;25(6):1553-62.

61. Bresciani G, Cuevas MJ, Garatachea N, Molinero O, Almar M, De Paz JA, et al. Monitoring biological and psychological measures throughout an entire season in male handball players. Eur J Sport Sci. 2010;10(6):377-84.

62. McHugh MP, Connolly D a, Eston RG, Gleim GW. Exercise-induced muscle damage and potential mechanisms for the repeated bout effect. Sports Med. 1999;27(3):157-70.

63. Howatson G, Milak A. Exercise-induced muscle damage following a bout of sport specific repeated sprints. J strength Cond Res. 2009;23(8):2419-24.

64. Young WB, Hepner J, Robbins DW. Movement demands in Australian rules football as indicators of muscle damage. J Strength Cond Res. 2012;26(2):492-6.

65. Gamble P. Strength and conditioning for team sports: sport-specific physical preparation for high performance. Routledge; 2013. 
66. Bahr R. Demise of the fittest: are we destroying our biggest talents? Br J Sports Med. 2014;48(17):1265-8.

67. Wisdom KM, Delp SL, Kuhl E. Use it or lose it: multiscale skeletal muscle adaptation to mechanical stimuli. Biomech Model Mechanobiol. 2015;14(2):195-215.

68. Eggli PS, Hunzinker EB, Schenk RK. Quantitation of structural features characterizing weightand less-weight-bearing regions in articular cartilage: A stereological analysis of medical femoral condyles in young adult rabbits. Anat Rec. 1988 Nov 1;222(3):217-27.

69. Kiviranta I, Jurvelin J, Tammi M, Säämänen AM, Helminen HJ. Weight bearing controls glycosaminoglycan concentration and articular cartilage thickness in the knee joints of young beagle dogs. Arthritis Rheum. 1987;30(7):801-9.

70. Slowman SD, Brandt KD. Composition and glycosaminoglycan metabolism of articular cartilage from habitually loaded and habitually unloaded sites. Arthritis Rheum. 1986;29(1):88-94.

71. Swann AC, Seedhom BB. The stiffness of normal articular cartilage and the predominant acting stress levels: implications for the aetiology of osteoarthrosis. Rheumatology. 1993;32(1):16-25.

72. Kubo K, Yata H, Kanehisa H, Fukunaga T. Effects of isometric squat training on the tendon stiffness and jump performance. Eur J Appl Physiol. 2006;96(3):305-14.

73. Couppé C, Kongsgaard M, Aagaard P, Hansen P, Bojsen-Moller J, Kjær M, et al. Habitual loading results in tendon hypertrophy and increased stiffness of the human patellar tendon. $\mathbf{J}$ Appl Physiol. 2008;105:805-10.

74. Prins J, Cutner D. Aquatic therapy in the rehabilitation of athletic injuries. Clin Sports Med. 1999;18(2):447-61. 
75. Haupenthal A, Ruschel C, Hubert M, De Brito Fontana H, Roesler H. Loading forces in shallow water running at two levels of immersion. J Rehabil Med. 2010;42(7):664-9.

76. Raffalt PC, Hovgaard-Hansen L, Jensen BR. Running on a lower-body positive pressure treadmill: VO2max, respiratory response, and vertical ground reaction force. Res Q Exerc Sport. 2013;84(2):213-22.

77. Kato T, Onishi S, Kitagawa K. Kinematical analysis of underwater walking and running. Sport Med Train Rehabil. 2001;10(3):165-81.

78. Hill-haas S V, Dawson B, Impellizzeri FM, Coutts AJ. Physiology of Small-sided games Training in Football: A Systematic Review. Sport Med. 2011;41(3):199-220.

79. Gaudino P, Alberti G, Iaia FM. Estimated metabolic and mechanical demands during different small-sided games in elite soccer players. Hum Mov Sci. 2014;36:123-33.

80. Hodgson C, Akenhead R, Thomas K. Time-motion analysis of acceleration demands of 4v4 small-sided soccer games played on different pitch sizes. Hum Mov Sci. 2014;33(1):25-32.

81. Buchheit M, Laursen P. High-Intensity Interval Training, Solutions to the Programming Puzzle. Part II : Anaerobic Energy, Neuromuscular Load and Practical Applications. Sport Med. 2013;43:927-54.

82. Gaudino P, Gaudino C, Alberti G, Minetti AE. Biomechanics and predicted energetics of sprinting on sand: Hints for soccer training. J Sci Med Sport. 2013;16(3):271-5. 